\title{
Diagnosis and Treatment of Status Epilepticus
}

\section{Review}

Journal of Epilepsy Research pISSN 2233-6249 / eISSN 2233-6257

Received October 14, 2020

Revised November 10, 2020

Accepted November 24, 2020

Corresponding author:

Sang Kun Lee, MD, PhD

Department of Neurology, Seoul National

University Hospital, 101 Daehak-ro,

Jongno-gu, Seoul 03080, Korea

Tel. +82-2-2072-2923

Fax. $+82-2-3672-7553$

E-mail; sangkun2923@gmail.com

\author{
Sang Kun Lee, MD, PhD \\ Department of Neurology, Seoul National University College of Medicine, Seoul, Korea
}

The definition of status epilepticus (SE) was revised recently in accordance with the various evidences of neuronal injury and changes in clinical settings. Currently, the most acceptable duration of continuous seizure activity is 5 minutes. In 2015, the International League Against Epilepsy Task Force, which was convened to develop a definition and classification of SE, presented a new classification based on four axes: 1) semiology, 2) etiology, 3) electroencephalogram (EEG) correlates, and 4) age. The essential element of nonconvulsive SE (NCSE) is the presence of neurological abnormalities induced by a prolonged epileptic process. The definition of refractory SE involves either clinical or electrographic seizures that persist after adequate doses of an initial benzodiazepine and acceptable second-line antiseizure drugs. The use of EEG is critical in the diagnosis and treatment of NCSE. However, there are a wide range of EEG abnormalities in NCSE. Both the Neurocritical Care Society and the American Epilepsy Society have suggested a paradigm for treating convulsive SE (CSE). The first-line treatment of CSE with benzodiazepine is well-established. The second-line treatment comprises intravenous (IV) doses of fosphenytoin (phenytoin), valproate, phenobarbital, levetiracetam, or midazolam. Although fosphenytoin (phenytoin) and valproate are commonly used in NCSE, the effectiveness of antiepileptic drugs (AEDs) on NCSE has not been well studied. New AEDs such as IV levetiracetam and lacosamide can also be used to treat NCSE with fewer side effects and drug-drug interactions. For refractory SE, general anesthesia with IV midazolam, propofol, pentobarbital, or thiopental could be applied. Use of ketamine, megadose phenobarbital therapy, and multiple combinations of various AEDs including high doses of oral AEDs can also be considered. New-onset refractory status epilepticus (NORSE) and its subcategory, febrile infection-related epilepsy syndrome, involve autoimmune processes. AEDs alone are poorly effective in the treatment of SE in autoimmune encephalitis. Immunotherapy such as steroids, immunoglobulin, rituximab, or tocilizumab can be effective. (2020;10:45-54)

Key words: Status epilepticus, Classification, Diagnosis, Treatment

\section{Definition and Classification}

The classical definition of convulsive status epilepticus (CSE) is continuous seizure activity for at least 30 minutes, or two or more recurrent convulsive seizures with incomplete recovery of consciousness between seizures. ${ }^{1}$ Recently, the definition of CSE was revised in accordance with the various evidences of neuronal injury and changes in clinical settings. Currently, the most acceptable duration of continuous seizure activities is 5 minutes. ${ }^{2,3}$ In fulfilment of the revised definition and classification of status epilepticus (SE), the 2015 International League Against Epilepsy (ILAE) task force stressed that $\mathrm{SE}$ is either the failure of the mechanism responsible for seizure ter- mination or the initiation of a mechanism leading to abnormally prolonged seizures, which can have long-term consequences. ${ }^{4}$ The framework of the new classification is based on four axes: 1) semiology, 2) etiology, 3) electroencephalogram (EEG) correlates, and 4) age (Table 1).

The definition of nonconvulsive SE (NCSE) is more controversial. The most common definition is electrographic seizure activity lasting for at least 30 minutes without visible convulsive movement. ${ }^{5,6}$ The essential element of the definition of NCSE is that neurological abnormalities are induced by a prolonged period of epileptic activity. ${ }^{4}$ The two key components of NCSE classification are absence SE (ASE) and complex partial SE (CPSE) (Table 2). ${ }^{7}$ NCSE can also be classified according to the age 
Table 1. Classification of status epilepticus by the ILAE task force ${ }^{4}$

\begin{tabular}{|c|c|c|}
\hline \multirow[t]{2}{*}{ Semiology } & $\begin{array}{l}\text { Presence or absence of prominent } \\
\text { motor symptoms }\end{array}$ & $\begin{array}{l}\text { A. Prominent motor symptoms } \\
\text { - Convulsive SE } \\
\text { - Myoclonic SE } \\
\text { - Focal motor status } \\
\text { - Tonic status } \\
\text { - Hyperkinetic SE }\end{array}$ \\
\hline & Degree of impaired consciousness & $\begin{array}{l}\text { B. Without prominent motor symptoms } \\
\text { - NCSE with coma } \\
\text { - NCSE without coma } \\
\text { Generalized: Typical or atypical absence status } \\
\text { Focal: Without impairment of consciousness (e.g., aura continua) } \\
\text { Aphasic status } \\
\text { With impairment of consciousness } \\
\text { Unknown whether focal or generalized } \\
\text { Autonomic SE }\end{array}$ \\
\hline \multirow[t]{2}{*}{ Etiology } & Known & $\begin{array}{l}\text { Acute (e.g., stroke, intoxication, encephalitis, etc.) } \\
\text { Remote } \\
\text { Progressive } \\
\text { SE in defined electroclinical syndrome }\end{array}$ \\
\hline & Unknown & Cryptogenic \\
\hline EEG & Six categories of EEG terminology & Location, pattern, morphology, time-related features, modulation, effect of intervention \\
\hline Age & & $\begin{array}{l}\text { Neonatal, infancy, childhood ( }>2 \text { to } 12 \text { years), adolescence and adulthood, elderly } \geq 60 \\
\text { years }\end{array}$ \\
\hline
\end{tabular}

ILAE, International League Against Epilepsy; SE, status epilepticus; NCSE, nonconvulsive status epilepticus; EEG, electroencephalogram.

Table 2. Simple classification of status epilepticus

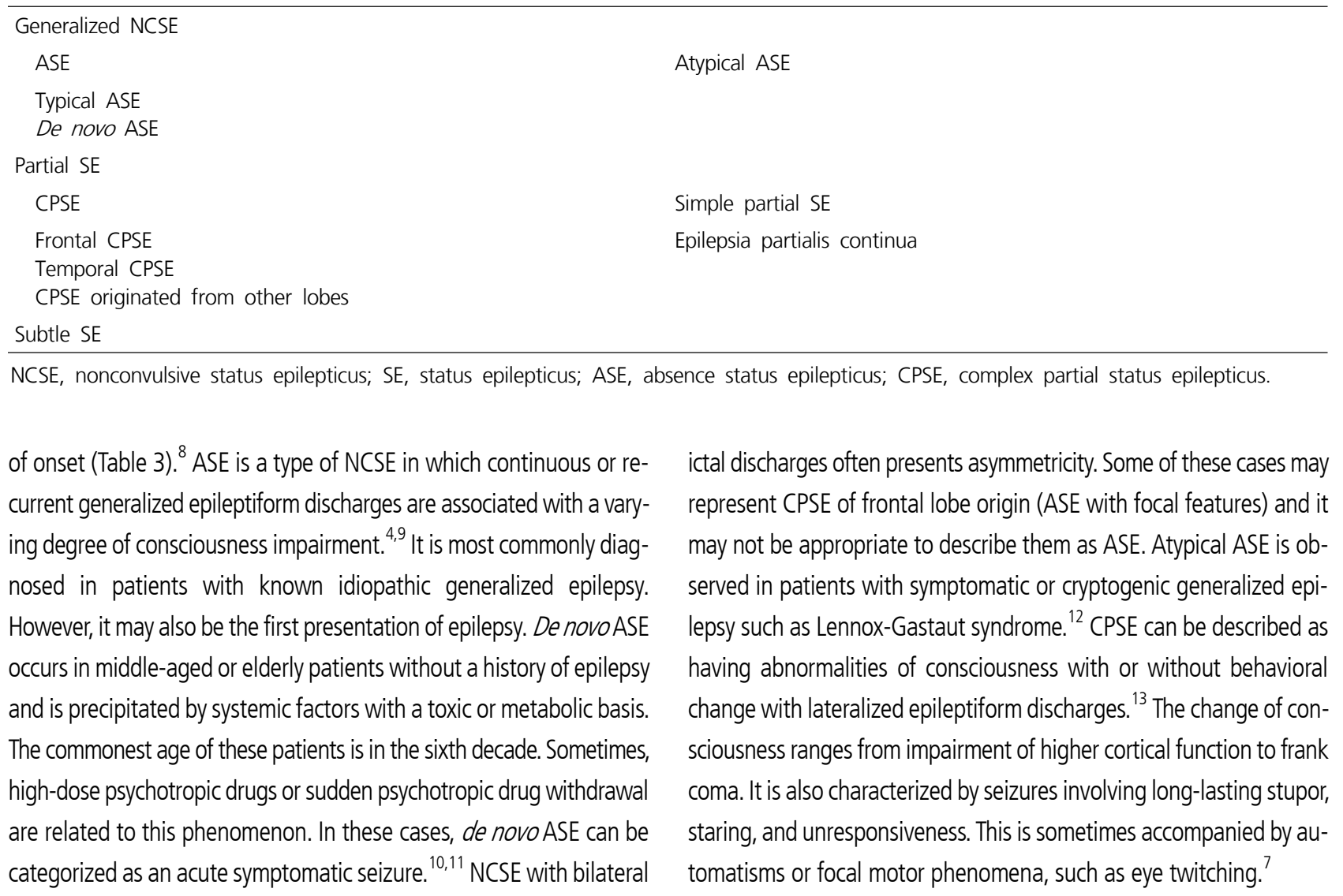


Table 3. Classification of NCSE according to age

\begin{tabular}{|c|c|}
\hline \multicolumn{2}{|l|}{ NCSE in the neonatal and infantile epilepsy syndromes } \\
\hline West syndrome & SMEI \\
\hline Ohtahara syndrome & NCSE in other forms \\
\hline \multicolumn{2}{|l|}{ NCSE occurring only in childhood } \\
\hline Panayiotpoulos syndrome & ESES \\
\hline NCSE in other forms of childhood epileptic encephalopathy & Landau-Kleffner syndrome \\
\hline \multicolumn{2}{|l|}{ NCSE occurring in both childhood and adult life } \\
\hline With epileptic encephalopathy & Without epileptic encephalopathy \\
\hline NCSE in Lennox-Gastaut syndrome & Typical absence status epilepticus \\
\hline Atypical absence status epilepticus & Complex partial status epilepticus \\
\hline Tonic status epilepticus & Limbic \\
\hline \multirow[t]{2}{*}{ Other forms of NCSE with learning disability or cerebral development } & Non-limbic \\
\hline & $\begin{array}{l}\text { NCSE in postictal phase of tonic-clonic seizures } \\
\text { Subtle status epilepticus } \\
\text { Aura continua }\end{array}$ \\
\hline
\end{tabular}

NCSE, nonconvulsive status epilepticus; SMEI, severe myoclonic epilepsy in infancy; ESES, electrical status epilepticus in sleep.

The definition of refractory SE (RSE) involves either clinical or electrographic seizures that persist after adequate doses of an initial benzodiazepine (BZD) and acceptable second-line antiseizure medication. ${ }^{14}$ Super-refractory SE (SRSE) is seizures continuing to recur 24 hours or more after the onset of anesthetic therapy. ${ }^{15}$ Subtle SE is the end stage of prolonged generalized tonic-clonic seizures (GTCS) ${ }^{16,17}$ Clinical features include focal or multifocal myoclonic movements, coma, periodic lateralized epileptiform discharges (PLEDs) with low voltage background, or continuous, rapid generalized epileptiform discharges with occasional flat periods. With advancing disease, these flat periods become longer. As an advanced stage of convulsive $\mathrm{SE}$, the prognosis is poor. There is a controversy whether subtle SE should be regarded as a type of NCSE.

\section{Clinical Manifestation and Diagnosis}

The clinical manifestation of CSE is overt. However, the diagnosis of NCSE is sometimes difficult and may be dependent on some important clues. ${ }^{8,18}$ NCSE may be followed by GTCS or CSE. Some stuporous patients show subtle signs such as twitching, blinking, and nystagmus. If otherwise unexplained stupor or confusion is observed, especially in older people, a diagnosis of NCSE should be considered. Sometimes, a history of seizures and a new medical or surgical stress can also provide clues to the diagnosis of NCSE. Some stroke patients show inappropriate altered mentality not fully explained by the lesion. This condition is called "stroke plus," which suggests that its symptoms were compromised with NCSE symptoms.
The criteria for the diagnosis of NCSE are controversial. ${ }^{19,20}$ NCSE can be summarized as a diminished level of consciousness or other neurologic deficit associated with epileptiform EEG of typical discrete seizures or continuous discharges. The response to antiepileptic drugs (AEDs) can be included in the diagnostic criteria. However, many NCSEs are refractory to AEDs both on EEG and on clinical presentation. Typical ASE has been described as an epileptic twilight state or spike-wave stupor. Three-quarters of patients are younger than 20 years of age. The onset is abrupt, without warning, and is sometimes associated with perioral or eyelid myoclonia, or limb myoclonus. Patients may be unaware of their environment with ambulatory automatism, poor communication, and variable amnesia. However, the clinical manifestations of atypical ASE present with fluctuating confusion with tonic, clonic, or sometimes focal-onset seizures. EEGs show bilateral asymmetric discharges of $<3 \mathrm{~Hz}$. ${ }^{9}$

CPSE is also known as prolonged epileptic fugue or prolonged epileptic twilight status. ${ }^{21-23}$ The change in consciousness ranges from mild clouding to unresponsive coma. There may be recurrent complex partial seizures with incomplete clearing between events or more continuous seizure activity and obtundation. CPSE may be associated with a twilight state with amnestic reactivity, complex reactive automatism, occasional alimentary automatism, perseverative gesticulation, and vocalizations. While symptoms of CPSE and ASE overlap considerably, some semiological differences may provide clues to the correct diagnosis. The cyclicity of semiology and the presence of fear, anxiety, irritability, aggression, and complex automatism favor the diagnosis of CPSE. Lip smacking, lateralized automatism, eye devia- 
tion, and nystagmus are also usually associated with CPSE. However, total unresponsiveness, speech arrest, cyclic behavior, and stereotypic nonlateralized automatism may also be present in both CPSE and ASE. 9,24 The categorization based on the clinical characteristics of patients such as the level of consciousness and ability to ambulate may sometimes be helpful to decide the urgency or the best types of drug to treat SE (Fig. 1).

The use of the EEG is critical in the diagnosis and treatment of NCSE. However, there are a wide range of EEG abnormalities in NCSE. Sometimes less-prominent semirhythmic slowing is the only EEG finding in NCSE. Some EEG findings are more suggestive of NCSE, while others are less suggestive (Fig. 2). ${ }^{19,20,25,26}$ The typical finding is focal or generalized spike-and-slow activity that usually waxes and wanes at a frequency of $>2 \mathrm{~Hz}$. Localized rhythmic delta and theta activity are also frequently found. While triphasic waves are the marker of metabolic encephalopathy, they also indicate the presence of NCSE. ${ }^{27}$ The response of triphasic waves to BZD may be helpful in the differential diagnosis between metabolic encephalopathy and NCSE. However, triphasic waves can be suppressed by BZD, even in metabolic encephalopathy. PLEDs on EEG classically suggest an acute destructive brain lesion. Triphasic waves can also be caused by the ictal rhythm itself. PLEDs are periodic epileptiform discharges, usually at a frequency of $<1 \mathrm{~Hz}$, often every $1-2$ seconds, some with intervals up to 10 seconds. Nine out of 10 patients have clinical seiz-

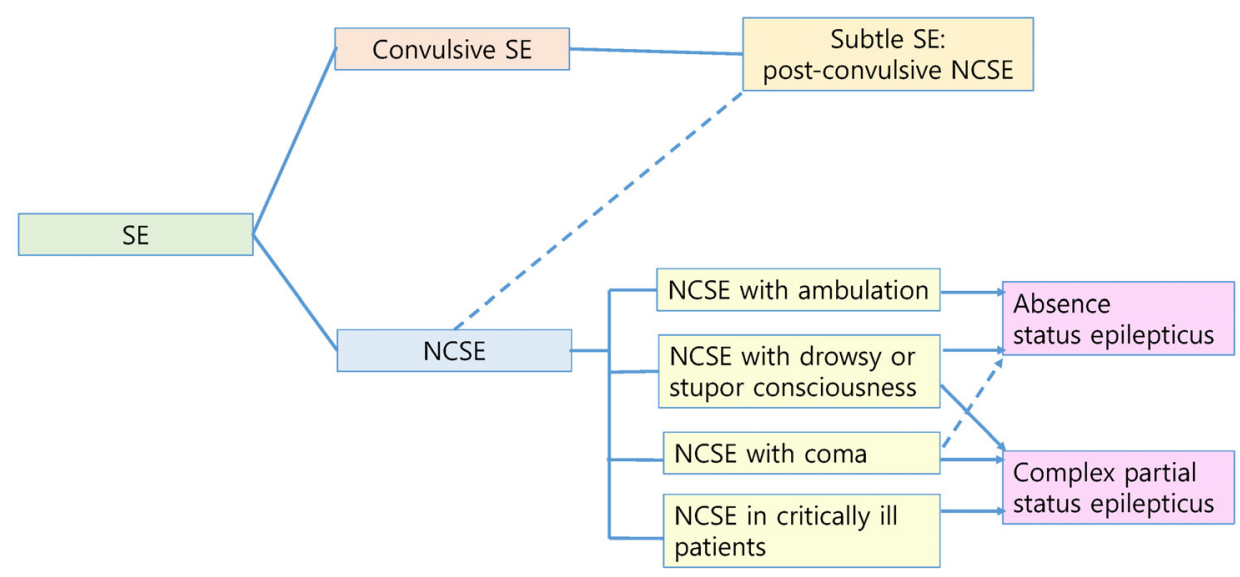

Figure 1. Categorization of SE according to the patient's status, such as level of consciousness and ability to ambulate. SE, status epilepticus; NCSE, nonconvulsive status epilepticus.

Possibility of NCSE

Recurrent
rhythmic activity with evolution

Focal or generalized spike-and-slow activity usually more than $2 \mathrm{~Hz}$, often waxing and wane

\begin{tabular}{|l|l|l}
\hline Rhythmic activity $>2.5 \mathrm{~Hz}$ & Rhythmic activity $<2.5 \mathrm{~Hz}$ \\
\hline
\end{tabular}

PLEDs $>1.5 \mathrm{~Hz} \quad$ PLEDs $<1.5 \mathrm{~Hz}$

Triphasic waves

Continuous irregular slowing

Figure 2. EEG of NCSE showing the increasing possibility of NCSE when approaching the left end. NCSE, nonconvulsive status epilepticus; EEG, electroencephalogram; PLED, periodic lateralized epileptiform discharge. 


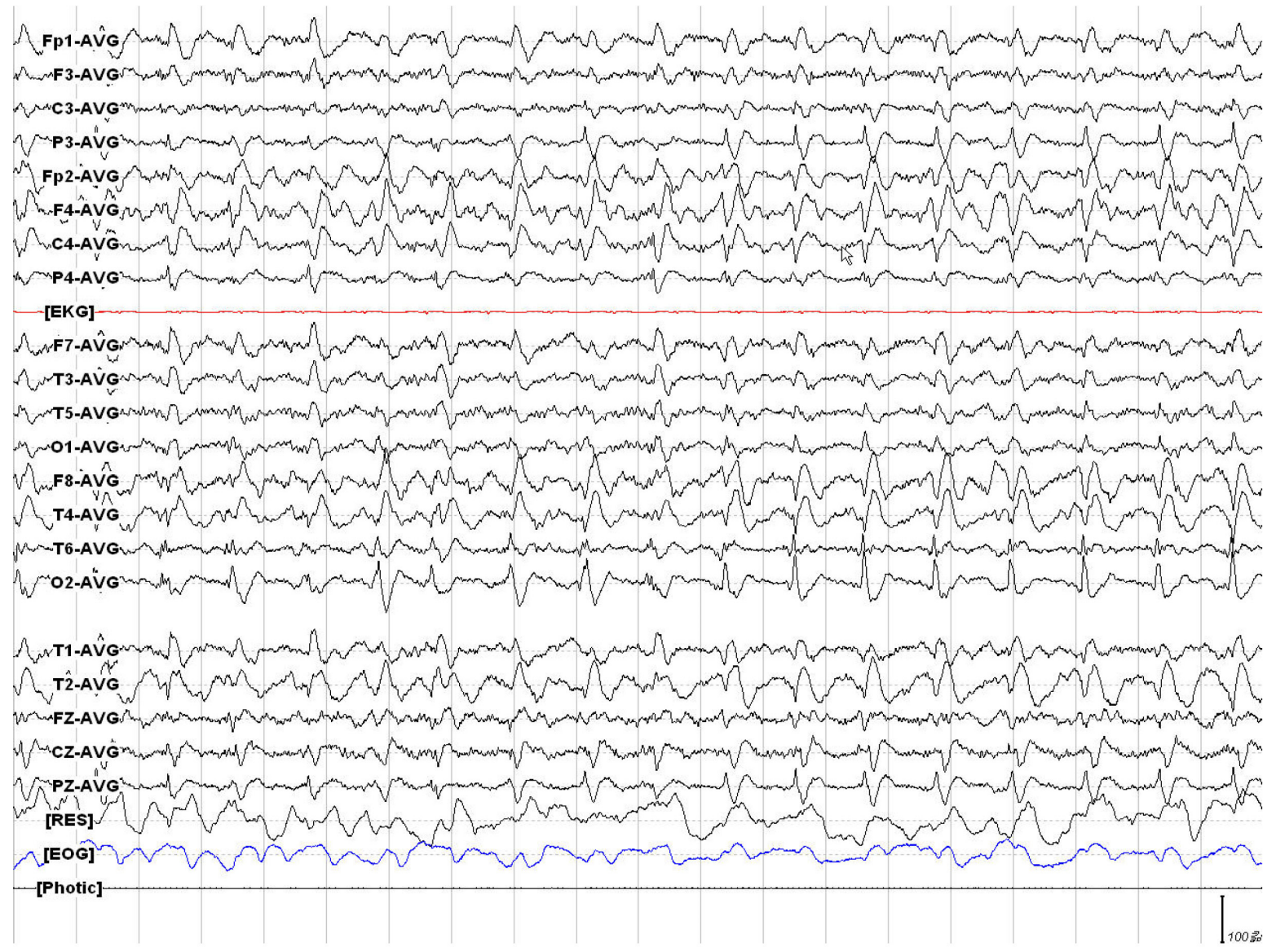

Figure 3. Example of periodic lateralized epileptiform discharges. See the periodic sharp waves at the frequency of $1 \mathrm{~Hz}$ in the right posterior area.

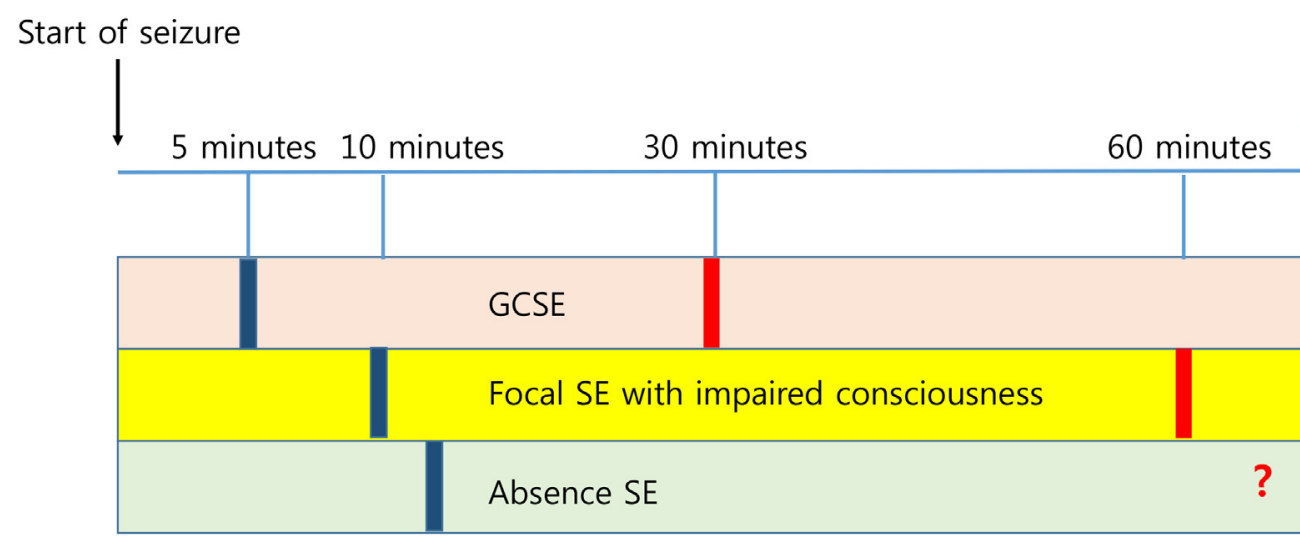

Treatment should be started (t1 by ILAE task force)

SE should be controlled (t2 by ILAE task force)

Figure 4. Acceptable time of initial treatment for various SE types recommended by the ILAE task force. ${ }^{4}$ GCSE, generalized convulsive status epilepticus; SE, status epilepticus; ILAE, International League Against Epilepsy. 


\section{Treatment}

Although clear features have not been identified, especially in NCSE, much experimental evidence indicates that irreversible brain damage arises after prolonged seizures. As a result, the 2015 ILAE task force recommended the 5-minute time point for the start of treatment (Fig. 4). ${ }^{4}$

\section{Treatment of CSE}

Both the Neurocritical Care Society and the American Epilepsy Society (AES) have suggested a paradigm to treat CSE (Fig. 5, Table 4). ${ }^{31,32}$ These two paradigms share almost identical frameworks that recommend similar AEDs with only slight differences in the administered dose. The AES recommends a time difference in dosing based on evidence derived from real-world situations.

The first-line treatment of CSE with BZD is well-established. The second-line treatment comprises intravenous (IV) fosphenytoin (phenytoin), valproate, phenobarbital, levetiracetam, or midazolam. Several studies have compared the efficacy of various AEDs in this situation (Table 5). ${ }^{33-38}$ IV lorazepam was superior to IV phenytoin for the control of CSE in a randomized controlled trial. ${ }^{33}$ IV lorazepam and diazepam showed equal efficacy, ${ }^{34}$ although lorazepam was favored because of its prolonged binding to GABA receptors. Midazolam was superior to lorazepam in one study, probably because of the shorter injection time of midazolam. ${ }^{35}$ IV levetiracetam was equally effective as IV lorazepam. Meta-analysis showed that IV valproate, phenobarbital, and levetiracetam were superior to IV phenytoin. ${ }^{36,37}$ Children, adults, and older adults with established SE respond similarly to phenytoin, valproate, and levetiracetam (about 50\%) in prospective randomized controlled trials. Levetiracetam and fosphenytoin were equally effective in the prevention of recurrent seizures after the control of CSE. ${ }^{38}$ Midazolam given via the intranasal, buccal, or intramuscular route may be as safe and effective as IV or rectal diazepam in terminating early-onset SE in children and potentially in adults. ${ }^{39}$

\section{Treatment of NCSE}

There is no universal consensus about how aggressively to treat NCSE. The etiology of NCSE is the most important prognostic factor in this disease. ${ }^{40} \mathrm{As}$ a result, it is difficult to assess the effect of NCSE alone on neuronal damage in human subjects. However, there is much evidence in animal models of neuronal damage in prolonged NCSE. ${ }^{41,42}$ The treatment paradigm is similar to CSE. In addition, when or how to apply anesthetic treatment of refractory NCSE is controversial.

Although fosphenytoin (phenytoin) and valproate are commonly used in NCSE, ${ }^{43}$ the effectiveness of AEDs on NCSE has not been well studied. New AEDs such as IV levetiracetam and lacosamide can also be used to treat NCSE with fewer side effects and fewer drug-drug interactions. The efficacy of lacosamide (usually $200-400 \mathrm{mg}$, IV) to treat SE has been assessed by systemic review ${ }^{43}$ and was found to be $61 \%$ for CSE and $57 \%$ for NCSE. The effectiveness of lacosamide to treat recurrent electrographic nonconvulsive seizure was compared with fosphenytoin (IV lacosamide 400 mg vs. fosphenytoin 20 mg; phenytoin equivalent $/ \mathrm{kg}$ ). This was a noninferiority, prospective, multicenter, randomized controlled trial that found lacosamide to be superior to fosphenytoin (63.3\% vs. $50 \%$ ) in preventing seizure re-

Table 5. AED comparison in the treatment of CSE

\begin{tabular}{|c|c|c|}
\hline Study & AEDs & Results (efficacy) \\
\hline US Department of VA cooperative study: $:^{33}$ RCT & IV lorazepam $0.1 \mathrm{mg} / \mathrm{kg}$ vs. IV phenytoin & Lorazepam > phenytoin \\
\hline Leppik et al..$^{34}$ (double blind study) & IV diazepam $10 \mathrm{mg}$ vs. IV lorazepam 4 mg & $\begin{array}{l}\text { Equal efficacy (diazepam } 76 \% \text { vs. lorazepam } \\
89 \% \text { ) }\end{array}$ \\
\hline RAMPART $T^{35}$ & 10 mg midazolam vs. 4 mg lorazepam & $\begin{array}{l}\text { Midazolam > lorazepam (probably rate } \\
\text { dependent) }\end{array}$ \\
\hline Yasiry and Shorvon ${ }^{36}$ (meta-analysis) & $\begin{array}{l}\text { IV valproate, IV phenobarbital, IV levetiracetam, } \\
\text { IV phenytoin (BZD refractory CSE) }\end{array}$ & $\begin{array}{l}\text { VPA }(75.7 \%) \text {, phenobarbital }(73.6 \%) \\
\text { levetiracetam }(68.5 \%)>\text { phenytoin }(50 \%)\end{array}$ \\
\hline ESETT (ongoing): ${ }^{37}$ prospective RCT & $\begin{array}{l}\text { Phenyoint, vlaporate, levetiracetam (BZD } \\
\text { refractory CSE) }\end{array}$ & \\
\hline Nakamura et al. ${ }^{38}$ & $\begin{array}{l}\text { Recurred seizure after control of SE by BZD: } \\
\text { levetiracetam vs. fosphenytoin }\end{array}$ & Equal efficacy \\
\hline
\end{tabular}

AED, antiepileptic drugs; CSE, convulsive status epilepticus; RCT, randomized controlled trial; IV, intravenous; BZD, benzodiazepine; VPA, valproic acid; SE, status epilepticus. 
currence $(p=0.02)^{44}$

\section{Treatment of RSE and SRSE}

For RSE, general anesthesia with IV midazolam, propofol, pentobarbital, or thiopental is recommended (Fig. 6). Continuous EEG monitoring is mandatory. When RSE is not controlled after 24-hour use of anesthesia, other options are available. Ketamine, ${ }_{1}^{45}$ megadose phenobarbital $^{46}$ therapy, and multiple combinations of various AEDs including high-dose oral AEDs can be considered. ${ }^{47-49}$ Oral AEDs such as topiramate, oxcarbazepine, and perampanel can also be used with a loading or high dose (Table 6).

The effect of BZD or other GABA agonists to control RSE is limited because GABA receptor internalization occurs ${ }^{50,51}$ after repeated seizures or continuous SE, which makes it impossible for GABA agonists to reach their receptors. High-dose phenobarbital may clear this hurdle. The advantage of megadose phenobarbital therapy is that less respiratory depression occurs compared with other anesthetic

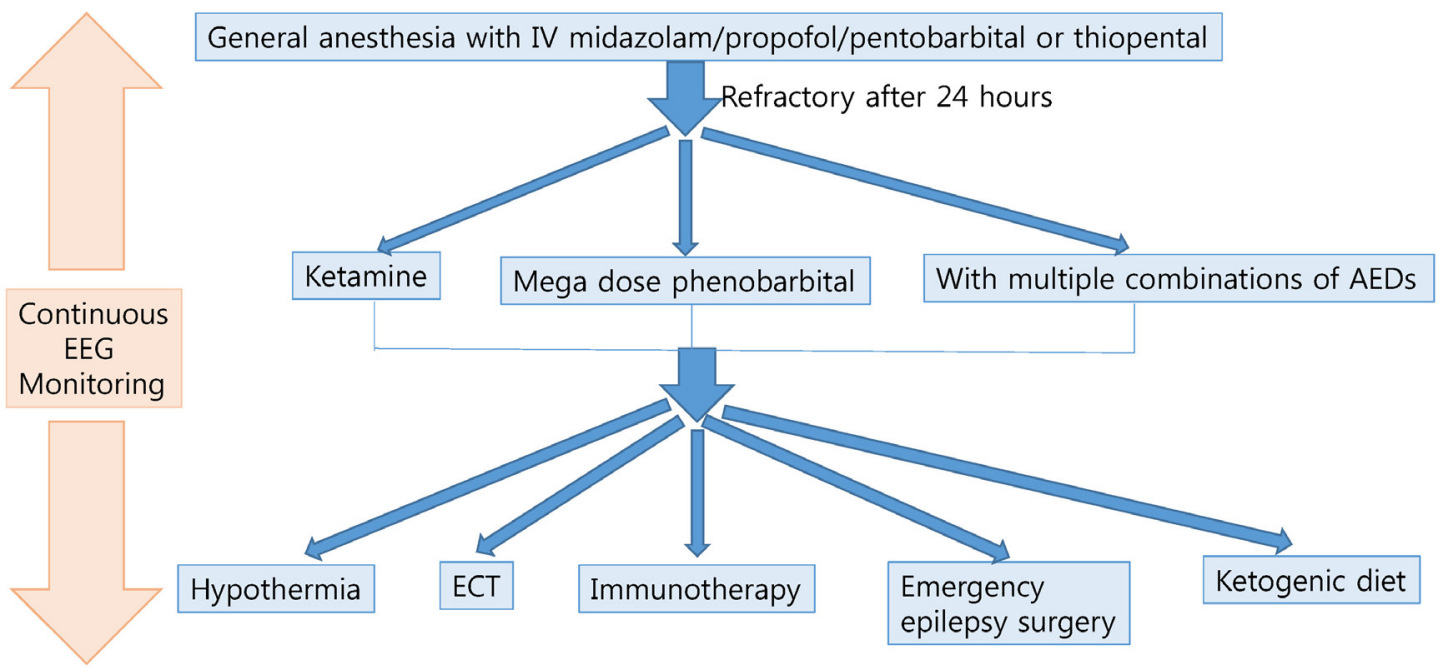

Figure 6. Suggested treatment algorithm for refractory status epilepticus and super-refractory status epilepticus. IV, intravenous; EEG, electroencephalogram; AED, antiepileptic drugs; ECT, electroconvulsive therapy.

Table 6. Oral antiepileptic drugs used in status epilepticus

\begin{tabular}{lll}
\hline AEDs & \multicolumn{1}{c}{ Loading dose } & \multicolumn{1}{c}{ Peak level after a single dose } \\
\hline Topiramate & $400-800 \mathrm{mg}$ & $1.5-2$ hours \\
Oxcarbazepine (MHD) & $30 \mathrm{mg} / \mathrm{kg}$ & $5-6$ hours (therapeutic range within 2 hours) \\
Perampanel & $4-32 \mathrm{mg}$ & $0.25-2$ hours \\
\hline
\end{tabular}

AED, antiepileptic drugs; MHD, monohydroxy derivatives.

Table 7. Other treatment options

\begin{tabular}{ll}
\hline Method & \multicolumn{1}{c}{ Consideration } \\
\hline Ketamine & Early use may have better prognosis \\
Isoflurane & No sustained effect \\
Ketogenic diet & Difficult compliance \\
Hypothermia & Coagulation disorders \\
Electroconvulsive therapy & \\
Mega dose phenobarbital & \\
Epilepsy surgery: focal resection & \\
\hline
\end{tabular}


therapy; therefore, it is suitable for long term use. Other special methods can also be considered for SRSEs that are resistant to these treatments, including application of hypothermia; electroconvulsive therapy; ketogenic diet; and emergency epilepsy surgery (Table 7).

\section{Immunotherapy}

Autoimmune processes have a vital role to play in SE. For example, some viral infections of the central nervous system can result in SE. Furthermore, the etiology of a recent increase in the number of SE cases can be explained by autoimmune encephalitis. ${ }^{52}$ Two special circumstances of SE are closely aligned with autoimmune processes. ${ }^{53-55}$ New-onset refractory SE (NORSE) is a clinical presentation that occurs in patients without active epilepsy or other preexisting relevant neurological disorder and no clear acute or active structural, toxic or metabolic disorder. Febrile infection-related epilepsy syndrome is a subcategory of NORSE. In both cases, a preceding febrile infection starts between 2 weeks and 24 hours before the onset of RSE. Other features suggesting an autoimmune etiology include acute or subacute onset, a history of preceding infection or trauma, the presence of anti-GABA A receptor antibodies, and a progressive course not responding to standard AEDs, but responsive to immunotherapy.

AEDs alone are largely ineffective in the treatment of SE in autoimmune encephalitis. Immunotherapy such as steroid, immunoglobulin, rituximab, or tocilizumab can be effective. In one study of six patients, NORSE was treated, without recurrence with one or two doses of tocilizumab with a median interval of 3 days from initiation. ${ }^{56}$

\section{References}

1. Treatment of convulsive status epilepticus. Recommendations of the epilepsy foundation of America's working group on status epilepticus. JAMA 1993:270:854-9.

2. Lowenstein $D H$, Bleck T, Macdonald RL. It's time to revise the definition of status epilepticus. Epilepsia 1999;40:120-2.

3. Brophy GM, Bell R, Classen J, et al. Guidelines for the evaluation and management of status epilepticus. Neurocrit Care 2012;17:3-23.

4. Trinka $E$, Cock $H$, Hesdorffer $D$, et al. A definition and classification of status epilepticus--report of the ILAE task force on classification of status epilepticus. Epilepsia 2015;56:1515-23.

5. Walker M, Cross H, Smith S, et al. Nonconvulsive status epilepticus: Epilepsy Research Foundation workshop reports. Epileptic Disord 2005; 7:253-96.

6. Husain AM. Treatment of recurrent electrographic nonconvulsive seizures
(TRENdS) study. Epilepsia 2013;54 Suppl 6:84-8.

7. Kaplan PW. Clinical presentations of nonconvulsive status epilepticus. In: Drislane FW, Kaplan PW, eds. Status epilepticus: a clinical perspective. 2nd ed. New York: Springer Nature, 2018;241-58.

8. Drislane FW. Presentation, evaluation, and treatment of nonconvulsive status epilepticus. Epilepsy Behav 2000;1:301-14.

9. Thomas P, Zifkin B, Andermann F. Absence status. In: Wasterlain CG, Treiman DM, eds. Status epilepticus: mechanisms and management. Cambridge: MIT Press, 2006;91-108.

10. Thomas $P$, Andermann $F$. Absence status in elderly patients is most often situation-related. In: Malfosse A, Genton P, Hirsch E, Marescaux C, Broglin D, Bernasconi R, eds. Idiopathic generalized epilepsies: clinical, experimental and genetic aspects. UK ed. London: John Libbey, 1994; 95-109.

11. Thomas P, Beaumanoir A, Genton P, Dolisi C, Chatel M. 'De novo' absence status of late onset: report of 11 cases. Neurology 1992;42:104-10.

12. Thomas P, Zifkin B, Migneco O, Lebrun C, Darcourt J, Andermann F. Nonconvulsive status epilepticus of frontal origin. Neurology 1999;52: 1174-83.

13. Kaplan PW. Behavioral manifestations of nonconvulsive status epilepticus. Epilepsy Behav 2002;3:122-39.

14. Bleck TP. Refractory status epilepticus. Curr Opin Crit Care 2005;11:117-20.

15. Shorvon S, Ferlisi M. The treatment of super-refractory status epilepticus: a critical review of available therapies and a clinical treatment protocol. Brain 2011;134(Pt 10):2802-18.

16. Rai $\mathrm{S}$, Drislane FW. Treatment of refractory and super-refractory status epilepticus. Neurotherapeutics 2018;15:697-712.

17. Meierkord $H$, Boon $P$, Engelsen $B$, et al. EFNS guideline on the management of status epilepticus in adults. Eur J Neurol 2010;17:348-55.

18. Shorvon S. What is nonconvulsive status epilepticus, and what are its subtypes? Epilepsia 2007;48 Suppl 8:35-8.

19. Herman ST. The electroencephalogram of nonconvulsive status epilepticus. In: Kaplan PW, Drislane FW, eds. Nonconvulsive Status Epilepticus. New York: Demos Medical Publishing, 2009;41-62.

20. Young GB, Jordan KG, Doig GS. An assessment of nonconvulsive seizures in the intensive care unit using continuous EEG monitoring: an investigation of variables associated with mortality. Neurology 1996;47:83-9.

21. Mikati MA, Lee WL, DeLong GR. Protracted epileptiform encephalopathy: an unusual form of partial complex status epilepticus. Epilepsia 1985; 26:563-71.

22. Markand ON, Wheeler GL, Pollack SL. Complex partial status epilepticus (psychomotor status). Neurology 1978;28:189-96.

23. Ballenger CE 3rd, King DW, Gallagher BB. Partial complex status epilepticus. Neurology 1983;33:1545-52.

24. Thomas P, Zifkin B, Andermann F. Simple and complex partial status epilepticus. In: Wasterlain CG, Treiman DM, eds. Status Epilepticus: Mechanisms and Management. Cambridge: MIT Press, 2006;69-90.

25. Chong DJ, Hirsch $\sqcup$. Which EEG patterns warrant treatment in the critically ill? Reviewing the evidence for treatment of periodic epileptiform dis- 
charges and related patterns. J Clin Neurophsiol 2005;22:79-91.

26. Kaplan PW. The EEG of status epilepticus. J Clin Neurophysio/ 2006;23: 221-9.

27. Brigo F, Storti M. Triphasic waves. Am J Electroneurodiagnostic Technol 2011;51:16-25.

28. Snodgrass SM, Tsuburaya K, Ajmone-Marsan C. Clinical significance of periodic lateralized epileptiform discharges: relationship with status epilepticus. J Clin Neurophysiol 1989;6:159-72.

29. Brenner RP. Is it status? Epilepsia 2002;43 Suppl 3:103-13.

30. Navarro V, Fischer C, Convers P. Differential diagnosis of status epilepticus. Rev Neurol (Paris) 2009;165:321-7.

31. Brophy GM, Bell R, Claassen J, et al. Guidelines for the evaluation and management of status epilepticus. Neurocrit Care 2012;17:3-23.

32. Glauser $T$, Shinnar $S$, Gloss $D$, et al. Evidence-based guideline: treatment of convulsive status epilepticus in children and adults: report of the guideline committee of the American Epilepsy Society. Epilepsy Curr 2016;16:48-61.

33. Treiman DM. The role of benzodiazepines in the management of status epilepticus. Neurology 1990;40(5 Suppl 2):32-42.

34. Leppik IE, Derivan AT, Homan RW, Walker J, Ramsay RE, Patrick B. Double-blind study of lorazepam and diazepam in status epilepticus. JAMA 1983;249:1452-4.

35. Silbergleit R, Lowenstein D, Durkalski V, Conwit R; Neurological Emergency Treatment Trials (NETT) Investigators. RAMPART (rapid anticonvulsant medication prior to arrival trial): a double-blind randomized clinical trial of the efficacy of intramuscular midazolam versus intravenous lorazepam in the prehospital treatment of status epilepticus by paramedics. Epilepsia 2011;52 Suppl 8:45-7.

36. Yasiry Z, Shorvon SD. The relative effectiveness of five antiepileptic drugs in treatment of benzodiazepine-resistant convulsive status epilepticus: a meta-analysis of published studies. Seizure 2014;23:167-74.

37. Chamberlain JM, Kapur J, Shinnar S, et al. Efficacy of levetiracetam, fosphenytoin, and valproate for established status epilepticus by age group (ESETT): a double-blind, responsive-adaptive, randomised controlled trial. Lancet 2020;395:1217-24.

38. Nakamura $K$, Inokuchi $R$, Daidoji $H$, et al. Efficacy of levetiracetam versus fosphenytoin for the recurrence of seizures after status epilepticus. Medicine (Baltimore) 2017;96:e7206.

39. Brigo F, Nardone R, Tezzon F, Trinka E. Nonintravenous midazolam versus intravenous or rectal diazepam for the treatment of early status epilepticus: a systematic review with meta-analysis. Epilepsy Behav 2015; 49:325-36.

40. Power KN, Gramstad A, Gilhus NE, Engelsen BA. Adult nonconvulsive status epilepticus in a clinical setting: semiology, aetiology, treatment and outcome. Seizure 2015;24:102-6.

41. Olney JW, Collins RC, Sloviter RS. Excitotoxic mechanisms of epileptic brain damage. Adv Neurol 1986;44:857-77.

42. Meldrum BS. Excitotoxicity and selective neuronal loss in epilepsy. Brain Pathol 1993;3:405-12.

43. Strzelczyk A, Zöllner JP, Willems LM, et al. Lacosamide in status epilepticus: systematic review of current evidence. Epilepsia 2017;58: 933-50.

44. Husain AM, Lee JW, Kolls BJ, et al. Randomized trial of lacosamide versus fosphenytoin for nonconvulsive seizures. Ann Neurol 2018;83:1174-85.

45. Rosati A, De Masi S, Guerrini R. Ketamine for refractory status epilepticus: a systematic review. CNS Drugs 2018:32:997-1009.

46. Byun JI, Chu K, Sunwoo JS, et al. Mega-dose phenobarbital therapy for super-refractory status epilepticus. Epileptic Disord 2015;17:444-52.

47. Kim DW, Gu N, Jang IJ, et al. Efficacy, tolerability, and pharmacokinetics of oxcarbazepine oral loading in patients with epilepsy. Epilepsia 2012; 53:e9-12.

48. Fechner A, Hubert $K$, Jahnke $K$, et al. Treatment of refractory and superrefractory status epilepticus with topiramate: a cohort study of 106 patients and a review of the literature. Epilepsia 2019;60:2448-58.

49. Ho CJ, Lin CH, Lu YT, et al. Perampanel treatment for refractory status epilepticus in a neurological intensive care unit. Neurocrit Care 2019; 31:24-9.

50. Walker MC. Pathophysiology of status epilepticus. Neurosci Lett 2018; 667:84-91.

51. Arya R, Rotenberg A. Dietary, immunological, surgical, and other emerging treatments for pediatric refractory status epilepticus. Seizure 2019; 68:89-96.

52. Spatola M, Novy J, Du Pasquier R, Dalmau J, Rossetti AO. Status epilepticus of inflammatory etiology: a cohort study. Neurology 2015;85: 464-70.

53. Sculier C, Gaspard N. New onset refractory status epilepticus (NORSE). Seizure 2019;68:72-8.

54. Gaspard N, Hirsch $\sqcup$, Sculier C, et al. New-onset refractory status epilepticus (NORSE) and febrile infection-related epilepsy syndrome (FIRES): state of the art and perspectives. Epilepsia 2018;59:745-52.

55. Hirsch $\sqcup$, Gaspard N, van Baalen A, et al. Proposed consensus definitions for new-onset refractory status epilepticus (NORSE), febrile infection-related epilepsy syndrome (FIRES), and related conditions. Epilepsia 2018;59:739-44.

56. Jun JS, Lee ST, Kim R, Chu K, Lee SK. Tocilizumab treatment for new onset refractory status epilepticus. Ann Neurol 2018;84:940-5. 